\title{
A trapdoor in the carbon cycle: the global implications of riverine carbonate chemistry
}

Knapp. W. J.1, SteVenson E. I., TipPeR. E.T.

1Downing St, Cambridge, CB2 3E,wjk27@cam.ac.uk

Despite carbonate rocks being the largest store of carbon at Earth's surface, carbonate chemistry is poorly understood in rivers as carbonate weathering is assumed to be carbon neutral[1]. However, the rapid dissolution of carbonate coupled to the long residence time of bicarbonate in the ocean $\left(10,000\right.$ years) is a useful short-term sink of $\mathrm{CO}_{2}$; possibly more useful than silicate weathering, as carbonate rock weathers almost instantaneously compared to silicates[2]. Carbonate rocks and river chemistry represent the largest carbon store on Earth's surface and can respond to anthropogenic climate forcing on timescales equivalent to a human lifetime, making carbonate weathering and transport in solution a critical facet of the modern? global cycling of carbon.

A large oversight of current methods that quantify weathering regimes in river basins (such as $\mathrm{Ca} / \mathrm{Na}$ ) is that they do not account for in-situ riverine processes, which skew the amount of $\mathrm{Ca}$ in solution. One example of such a process is the precipitation of calcite within river basins, which removes $\mathrm{Ca}$ from solution. Here we present stable isotope and trace metal analyses from the highly alkaline Huveaune river (Provence, France), which is actively precipitating carbonate travertines. Solution chemistry in the Huveaune is dominated by carbonates, presenting an ideal testbed for understanding the impact of carbonate precipitation on river water chemistry. Our study here is an attempt to elucidate how carbonate is removed from solution and to quantify the magnitude and rate of precipitation using a combination of novel stable isotope geochemistry $\left(\delta_{44} \mathrm{Ca}, \delta 88 \mathrm{Sr}, \delta 26 \mathrm{Mg}\right)$ and reactive transport modelling.

References: [1] Berner, E.K. and Berner, R.A., 2012. Global environment: water, air, and geochemical cycles. Princeton University Press. [2] Lasaga, A.C., 1984. Chemical kinetics of water-rock interactions. Journal of geophysical research: solid earth, 89(B6), pp.4009-4025. 
This abstract is too long to be accepted for publication.

Please revise it so that it fits into the column on one page. 